SBM

8,5

\section{Making knowledge work - best papers from the Managing Sport SIG at the European Academy of Management (EURAM) Annual Meeting in Glasgow 2017}

The 2017 edition of the EURAM conference was held under the motto "making knowledge work". In the context of sport management this motto makes a lot of sense. Academic research around sports as industry and manageable activity has come up in the 1990s in the USA. Soon after these early stages of sport management research, scholars from various backgrounds including business, economy, sociology and others became interested in studying phenomena in sports related to economy, management and marketing. From the beginning, scholars in sport kept a focus on the managerial and practical implications as well as to theory development. Making knowledge - gained from rigorous research - work to help practitioners to better manage mass or elite sport development, sport events and tourism organisation, or sport business strategy and development has been a predominant paradigm in the field of sport management.

The 2017 edition of the Annual Meeting of EURAM and the Managing Sport SIG kicked off with a symposium discussing critical issues in sport. Speakers for this kick-off event were Rasmus Storm, Harry Arne Solberg and Stephen Morrow. Rasmus Storm provided in-depth insights into the variations of impact of sport scandals while Harry Arne Solberg analysed the numerous organisational failures happening throughout sport events. Stephen Morrow closed the event with a presentation on the role of an uncertain political environment on sport events, highlighting the Brexit, independence movements and political decisions by new governments such as the Trump administration in the USA.

The symposium followed three days of rich presentations and discussions. Overall, 21 papers were presented in seven different sessions. We selected six best papers for this special issue. This selection was based on the overall reviewer scores and the general theme. It includes the paper that won the Emerald Best Paper Award and that was submitted to the Managing Sport SIG's conference programme by Konstantinos Koronios, Maria Psiloutsikou and Thanos Kriemadis entitled "An exploration of motives, constraints, and future participation intention in mass running events". The authors conducted an impressive empirical work and found that intrapersonal constraints influence motivation factors and that motivation factors influence the intention for continuous participation in mass running events in a Greek context. To link back to the motto of the conference, the results are of high interest for mass running event organisers.

Amongst the two best paper runner-up were the submission of Charitomeni Tsordia, Dimitra Papadimitriou and Artemisia Apostolopoulou with their paper on "Building a sponsor's equity through brand personality: perspectives of fans and rivals". The original contribution of this paper is the introduction and analysis of the concept of brand personality as a means to enhance sponsors' brand equity not only for the sponsored team's fans but also for the rivals' team fans. The authors offer interesting managerial implications for marketing managers of both sponsors and sponsees.

The second runner-up was the paper submitted by Lobone Kasale, Mathieu Winand and Leigh Robinson on "Performance management of national sport organisations (NSO): a holistic theoretical model". The purpose of this paper is threefold: first, to provide an understanding on the performance management practices existing among NSO, second, to identify key elements that play a role in the process and third, to conceptualise performance An International Journal pp. $434-435$

(C) Emerald Publishing Limited 2042-678X

DOI 10.1108/SBM-11-2018-090
Sport, Business and Management:

\section{Guest editorial} Vol. 8 No. 5, 2018

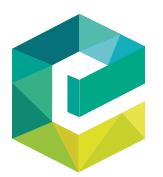


management of NSOs from a holistic point of view. The authors develop a model that aims at helping managers of NSO to improve their performance management processes.

Another paper dealing with sport institutions is included in this special issue submitted by Mikhail Batuev and Leigh Robinson. The paper title is "What influences organisational evolution of modern sport: the case of skateboarding" and deals with the process of organisational evolution of a modern sport - skateboarding - with regard to three dimensions: values of the activity, commercial interests and the Olympic movement. It is an in-depth case study providing insights on the commercialisation, professionalisation and institutionalisation processes of a modern sport by taking into account the sport's stakeholders and particular values. Transformational developments such as sportification and eventification of traditionally non-sport activities are new phenomena and traditional sport institutions need to understand better how to deal with them to avoid interinstitutional conflicts.

The two remaining papers that we included in this special issue are literature reviews. First, there is the paper by Maurizio Valenti, Nicolas Scelles and Stephen Morrow on "Women's football: an integrative review and new research dimensions". This paper systematically reviews and synthesises research approaches, findings, frameworks and implications of women's football literature. This article provides an overview about existing knowledge on women's football and identifies gaps for future research.

Finally, this special issue closes with the paper submitted by Christofer Laurell and Sten Söderman with the title "Sport in business studies: a state-of-the-art literature review". This paper provides a systematic review of articles on sport published in leading business studies journals. It provides insights in the current presence of sport-related studies in the larger business studies environment and provides evidence for the increasing attention paid to sport management not only as an empirical context but also as an academic discipline.

We are grateful to Emerald Group Publishing for continuing the strong bonds between Sport, Business and Management and the Managing Sport SIG not only by sponsoring the annual Best Paper Award but also the Best Reviewer Award. The Best Reviewer Award went to Alana Thomson and the runner-up was Dimitrios Kolyperas. Congratulations. The Award Committee for both the Best Paper and Best Reviewer awards included Sten Söderman (Past SIG Chair) and Simon Gérard (Best Paper Runner-up 2016). Finally, we would like to thank this committee but also all the contributors and anonymous reviewers of conference papers for their excellent work.

Anna Gerke

Department of Management, Audencia Business School, Nantes, France, and

Mathieu Winand LUNEX International University of Health, Exercise and Sports, Luxembourg 